Revista Iberoamericana, Vol. LXXIV, Núm. 223, Abril-Junio 2008, 333-341

\title{
VIOLENTAMENTE COLOMBIA
}

\author{
POR \\ JEFFREY CEDEÑo \\ Universidad Simón Bolívar-Caracas \\ Maite Villoria Nolla \\ University of West Indies-Mona Campus
}

Pontificia Universidad Javeriana-Bogotá

La vida en América Latina resulta, para muchos, difícil. Se trata de una vida anclada, sin embargo, en una certeza: la imposibilidad de conciliarse con una realidad cuya contundencia aparece por doquier. La violencia, en sus disímiles formas, nombra tal dificultad pues traza disposiciones, clausura millones de destinos, y de este modo define y cruza y altera nuestras vidas. No se trata, en modo alguno, de un inicio; presenciamos más bien una clausura cuyo poder no ofrece alternativas e interroga, quizás inútilmente, nuestras acciones, nuestro discurso, nuestra humanidad... todo un entramado cuyos alcances rehuyen toda fijeza, toda frontera.

Colombia se consume trágicamente en la violencia, ya hereditaria, ya familiar, nacional. Hoy, los colombianos atestiguan un ritual trágico y espectacular, por no decir cotidiano y trivial, y es que toda mirada vuelve a su sentido etimológico -admirarse- para tratar de comprender las posibilidades que aún ofrece la vida. Y la violencia es una de ellas. Michel de Certeau, advierte:

\begin{abstract}
Antes de elaborar teorías sobre la violencia, antes de hacer su apología, como si fuera un valor o un fin en sí misma [...] hay que reconocerla como un hecho que tiene su importancia. Una cosa es constatar en el conflicto un elemento imposible de eliminar de la experiencia humana y, en la actual escalada de violencia, una reivindicación tan esencial que renunciar a ella significaría perder el derecho y el gusto de existir (hay causas que valen más que la propia vida); y otra es hacer de la violencia una ley -posición contradictoria que llevaría a olvidar por qué se lucha, que quitaría todo sentido a la lucha, privándola de objetivos verdaderamente políticos, que renunciaría a la instauración revolucionaria frente a los riesgos que sería necesario compartir, y que rebajaría la voluntad de llegar a ser una mera colectividad de seres humanos anclados apenas en una "ley" bestial (o natural) de un struggle for life. (29)
\end{abstract}

Colombia, más allá de todas las distancias que convocan los juicios de de Certeau, pareciera consumirse en tales sinuosidades y al mismo tiempo las excede, a tal punto que sus efectos no conocen límites, y por lo tanto el tiempo se multiplica una y otra vez, marcando los ritmos de vida de millones de colombianos. El presente volumen, titulado Violentamente Colombia, solo pretende señalar la contundencia de una manera de operar y de hacer que en un principio, deja por fuera lo natural y lo propio, pero en su reverso, afirma y autoriza 
con ímpetu la posibilidad misma de la acción, de un inicio otro más allá (o más acá) de la violencia y sus disímiles instrumentos. Los artículos reunidos aquí tan solo trazan líneas inabarcables, y testimonian una mirada crítica que en modo alguno desconoce que la naturaleza y la cualidad de las relaciones (des)armadas por la violencia en sus múltiples frentes y desde sus varios actores, sólo ofrecen interrogantes cuyas respuestas aún hoy, no descartan la vida como posibilidad.

La primera sección del volumen, titulada "Los rastros de la Nación y una cultura violenta para las masas”, reúne cuatro ensayos que, en conjunto, trazan un arco histórico capaz de exhibir las diferentes voces ocupadas en develar las conflictivas figuraciones de la Nación colombiana en el fin del novecientos: de la historiografía a la ficción, desde la vida hasta la muerte cruzadas por el relato, Colombia hilvana una cruda y masiva travesía de la violencia en la formación de destinos individuales y colectivos. En "Nación y Narración de la violencia en Colombia (de la historia a la sociología)”, María Helena Rueda estudia la representación textual de la violencia -la historiografía nacional desde el siglo xIx hasta el xx- y su relación con la concepción moderna de la Nación. Para Rueda, el tránsito histórico indicaría una "crisis" en las narrativas de lo nacional inscritas por los procesos de modernización, la cual se manifiesta justamente cuando se inicia el discurso sobre la “violencia”. Así, desde Historia de la Revolución en la República de Colombia (1858), de José Manuel Restrepo, hasta La violencia en Colombia (1962), de Germán Guzmán Campos, Orlando Fals Borda y Eduardo Umaña Luna, surge al punto un problemático discurso sobre la violencia "porque tiende a toparse con un territorio en el que reina el silencio, donde se encuentran los muertos causados por el objeto de estudio. Ese mismo silencio puede entenderse también, sin embargo, como un impulso que alienta el deseo de elaborar una escritura al respecto [...] Paradójicamente, asumir la incapacidad del discurso para deshacer los actos de violencia puede ser un camino para entender su acción, señalar la responsabilidad de quienes los promueven y minimizar el daño que causan”. Sin duda, surge al punto la "Nación” como un problema ocupado en interrogar el lugar social, político, económico y cultural de la violencia dentro de los procesos de modernización nacional. Se abre, desde aquí, y como bien lo exhibe la autora en su artículo, una pregunta por la identidad en sus múltiples aristas históricas y culturales.

“¿Cómo inscribir [...] las voces silenciadas por el reino del terror?”, constituye una de las mayores inquietudes de Francisco Ortega en "Sin orden ni final. Escritura y desastre. Representación de La Violencia en Colombia”. Desde una lectura detallada de Estaba la pájara pinta sentada en el verde limón (1976), de Alba Lucía Ángel, Ortega interroga los límites de los conceptos de historia y ficción a la hora de enfrentar la pregunta por la verdad. Para el autor, conocer y reconocer la historicidad en sus múltiples visiones resulta clave, por ello recupera un origen decisivo dentro de la vida colombiana del novecientos: el asesinato del candidato presidencial Jorge Eliécer Gaitán en Bogotá el 9 de abril de 1948, todo lo cual "provoca una estallido de furia colectiva en la ciudad, posiblemente sin precedentes, que rompe la historia del país en dos e instaura de manera decidida e irrecusable la violencia social como protagonista central de nuestra historia política”. Desde allí, Estaba la pájara pinta..., logra transitar la violencia al articular una miríada de voces sociales con el fin de evaluar no sólo una dimensión autobiográfica, también todo discurso de formación capaz de 
otorgarle coherencia al mundo social. De este modo, la novela de Ángel narra vidas que se han manifestado catastróficas y que se rehúsan a integrarse en un relato de orígenes. Dice el autor: "Esas vidas desastradas socavan los códigos de la historiografía nacional al privilegiar rupturas, ruinas, reticencias, en suma, al mostrarse escéptico con la deseada coherencia social de toda historia política”. Se trata, sin duda, de un enfrentamiento discursivo con la noción misma de lo real: la novela de Ángel “es a la vez un encuentro fallido con lo real y un estallarse ante ese real; en esa doble condición podemos entenderla como escritura del desastre”. Esta reorganización simbólica surge, justo, cuando nos enfrentamos a la violencia por medio de las aristas de la narración.

En "Subjetividades subyugadas: resentidos, arrimados, huidizos, sufrientes y desechables”, dos conceptos esenciales del liberalismo clásico organizan la reflexión de Ileana Rodríguez: sociedad civil y esfera pública. Su conmensurabilidad o no surge al punto para, como bien lo sostiene la autora, autorizar un discusión sobre la democracia y la gobernabilidad, visto desde el fenómeno de la "Violencia" en Colombia. Sobre la base de los testimonios compilados por Alfredo Molano -Mujeres de fuego (1978), Los años del Tropel (1985) y Trochas y fusiles (1994)-, Rodríguez explora el desfase entre teoría política y formación social justo cuando traza una clara “violencia epistémica” ocupada en auscultar el relato y... la vida: "Pues es en el relato de vida tanto como en la vida misma del informante donde encuentro la concurrencia de una teoría cuya praxis está subyugada. Es ahí, en la vida de los públicos campesinos y sus prácticas, donde se encuentra el terreno en el que convergen teoría política, prácticas y formaciones sociales liberales. Ese cambio de planos enunciativos establece un saber ligado a la supervivencia, pero también al sentido de lo político y de lo público”. Pero la autora también alcanza los efectos materiales de una realidad contundente, multiplicada en la vida de miles de campesinos colombianos: "la discusión pública en lugar de conducir a la democratización conduce a la radicalización. Y esto sucede porque a las tácticas civilistas de los sin tierra se les responde no con la discusión sino con la fuerza. Es esta una dinámica que radicaliza simplemente porque a la democracia se le pone obstáculos”, y cuando las formalizaciones alternas fallan, el campesino "se va a la guerra, a la delincuencia, al crimen, y al terror. Este es el final de la etapa de la razón discursiva y el comienzo de la razón armada, el fin de la lucha discursiva por la democracia y el principio de la fuerza que opone la fuerza”. Surge entonces un orden otro cuyo nombre, la vida, fractura fronteras instituidas justo para sobrevivir.

Pensar el nudo relaciones que traman las masas en relación con la vida y las formas de propiedad en el contexto de la multiforme violencia colombiana de las últimas décadas, constituye el objetivo central de Jeffrey Cedeño y Maite Villoria Nolla en el artículo "Una clausura para las Masas: vida y propiedad”. Desde una perspectiva cultural, el trabajo de Cedeño y Villoria Nolla examina el cambiante lugar de las masas dentro del juego de las relaciones sociopolíticas hasta alcanzar, en contrapunto, fines personales y sectoriales en franca lucha por la propiedad, todo lo cual permitirá tramar otras lecturas significantes para la comprensión de la violencia colombiana como un fenómeno de masas articulado dentro de los procesos de globalización económica: "Sí resulta evidente que, en el contexto colombiano, como en muchos otros países de América Latina, la propiedad sigue lo económico para ajustar definiciones sobre la vida, todo lo cual interroga fuertemente la 
política y la democracia desde sus determinaciones sociales y culturales. No obstante [...] la violencia colombiana recrudece y singulariza una condición extendida: la vida es la simple y única propiedad con la que cuentan millones de personas ante la avanzada de la violencia en todos sus frentes, y aquí, los medios-fines de la política y la economía, cualquiera sea la ideología que las colma, se sitúan de espaldas a la vida, y sirven de muy poco". El artículo concluye con una reflexión crítica sobre los significados de la vida en un país clausurado por una violencia expansiva; significados que vistos desde la política y la economía, ejercen una interrogación sobre la cultura colombiana de entre siglos, no tanto para manifestar duda o pedir una respuesta, sino para expresar con vigor y eficacia los crudos espejismos de una comunidad nacional.

En la sección titulada "La trama de la violencia y las historias interpretadas", reunimos varios análisis críticos que intentan capturar las historias que recorren las vidas cruzadas por la violencia. No se trata, en modo alguno, de una tarea fácil porque situarse en los extremos deja salir sin trabas una densidad francamente irrepresentable, pero sin duda esparcida -por no decir desplazada- en disímiles discursos culturales. Así, por ejemplo, Juana Suárez en su artículo “'En átomos volando’: transformaciones de la iconografía patriótica en la producción cultural colombiana”, describe y discute la apropiación y deconstrucción de la iconografía nacional conflictivamente cruzada entre lo popular y lo estatal. Desde varios objetos discursivos -ejemplos musicales, medios de comunicación, manifestaciones de humor y películas- Suárez traza un punto común: se trata de una producción cultural capaz de ofrecer una contra-narrativa a la retórica de la nación, todo lo cual deshace un tiempo histórico unificado y oficial y, de este modo, interroga las aristas del imaginario cultural de la Nación. Para la autora: "Ubicados en las contradicciones de la disyunción global, estos productos culturales y su hibridez son reiterativos de la necesidad de desmovilizar el concepto unívoco de "cultura nacional” y de pensar la nación no desde lo homogéneo sino desde su diversidad. Martín-Barbero ha criticado insistentemente la obsesión del sujeto nacional con 'la buena imagen del país', preocupación que se ha extendido (y viciado) diversas discusiones y debates críticos sobre Colombia y que relativamente traduce la ceguera de ciertos sectores para entender la liminidad cultural del país”. De acuerdo con Suárez, los límites de la iconografía nacional trazan los contornos de un proceso de inclusión y exclusión en relación con la ciudadanía y las formas de violencia que la auscultan. Surge al punto entonces un reconocimiento franco y certero: "entender la 'cultura nacional' como un espacio de reflexión y reconstrucción a partir del reconocimiento de nuestras llagas”, para, y desde allí, alcanzar otra figuración de una identidad múltiple y siempre en franca reinvención. Por su parte, Luz Mary Giraldo, en "Narradores colombianos y escrituras del desplazamiento. Indicios y pertinencias en una historia social de la literatura”, estudia desde una perspectiva histórica las entrecruzadas formas que convoca la multiforme y expansiva violencia colombiana a la hora de trazar una decisión: migrar del campo a la ciudad, de la ciudad a otras fronteras. Se trata de un sujeto migrante y desplazado siempre tras un "nuevo (des)orden": multiplicidad, heterogeneidad e inestabilidad capturadas por una literatura que frente a tal violencia, no duda en dar cuenta de sus propios desplazamientos: "Si aceptamos que la historia de nuestro desplazamiento es incesante, las ficciones sobre el tema en distintas épocas nos pueden ofrecer el por qué, el para qué y el cómo de cada 
momento y cada autor”. De allí, se entiende, la amplia arqueología de la literatura colombiana contemporánea que inscribe la autora a la hora de analizar una narrativa cuya significación trasciende lo inmediato, la cultura de la imagen y el vacío, para, de este modo, alcanzar sus palabras en la errancia, el desarraigo, la desunión familiar y la pérdida. Justo en esta carencia multiplicada que convoca la violencia, la literatura colombiana construye su historia, su identidad: "Esta tendencia narrativa de entre siglos, abierta a fines del xix y aún si cerrar en los comienzos del xxi y tantas veces contada, demuestra que la historia literaria no puede desprenderse de la historia social ni de la literatura, y que el agobio de una situación no sólo reclama unas recreaciones, sino unas formalizaciones que retomen los imaginarios de cada momento, de cada autor y de cada generación. En los indicios puede estar la clave para una lectura pertinente que atañe a la historia de la literatura; al ponerlos en diálogo con otros discursos se clarifican pertinencias e impertinencias de la necesidad de comprender la evolución y el desarrollo de unos temas y unas formas en nuestro contexto".

Con base en el pensamiento de Jacques Derrida y la teoría de la complejidad -de Paul Cilliers y Nigel Clark-, Nicholas Goodbody en "La emergencia de Medellín: la complejidad, la violencia y la différance en Rosario Tijeras y La Virgen de los Sicarios", establece cómo el discurso ficcional y el sociológico trazan un diálogo con la ciudad y la violencia. Un diálogo entrecruzado surge al punto o, mejor aún, un sistema complejo en el que la ciudad, concebida como un efecto de las relaciones entre los seres humanos, "no es meramente un trasfondo para la sicaresca [término derivado de la picaresca española] del cual podemos extraer y analizar una noción abstracta de la violencia; es una parte integral de ella, el ambiente del que ella nace y en el que cobra su carácter”. Goodbody sostiene que el contrapunto ficción/sociología de la violencia no se consume en una bifurcación insalvable, "Más bien, son perspectivas suplementarias sobre el fenómeno de la violencia urbana. Mientras la sociología se enfoca en la búsqueda de causas, consecuencias y soluciones concretas, novelas como Rosario Tijeras y La virgen de los sicarios nos enseñan los modos de interpretación que se encuentran más allá de las fronteras del pensamiento analítico y la relación problemática que uno comparte con su contorno”. El autor plantea que todo lenguaje y discurso sobre la violencia no sólo la describe, también la evalúa y la constituye. Se trata, entonces, de un lenguaje cuyas redes disuelven toda jerarquía vertical para alcanzar asociaciones no lineales -sin origen y sin destino-, pero que, sin embargo, en su incesante performatividad, logran capturar una memoria capaz de anudar y cristalizar una miríada de experiencias culturales.

En "El cine urbano y la tercera Violencia colombiana”, Geoffrey Kantaris subraya la categoría sistémica de la violencia -en tanto “efecto de la representación” y “sistema de representación”-vista desde la tercera fase de la violencia colombiana: la aquélla que alcanza la urbe y sus imaginarios. El autor centra su interés en la filmografía del fin de siglo xx, y a partir de Pura sangre (1982), de Luis Ospina; La virgen de los sicarios (1999), película basada en la novela homónima de Fernando Vallejo, y dirigida por Barbet Schröder; y Sumas y restas (2004), la última película de la trilogía sobre Medellín, dirigida por Víctor Gaviria, sugiere que "la violencia que se registra en el cine urbano colombiano es de orden más sintomático", es decir, "lo sintomático sería la antítesis de lo fetichista, puesto que los modos de representación fetichistas dependen muy precisamente de un proceso más o 
menos perfecto de ocultación o denegación del síntoma. Una lectura sintomática de la violencia -y estas películas son una lectura en este sentido- de igual modo que una lectura alegórica, insiste en el desplazamiento y la dislocación, la violencia no como una pantalla (de la identidad del macho fuerte, por ejemplo) sino como un corte en la pantalla, la forma presente de otra escena”. Al trascender cualquier fetichismo de la violencia, los filmes analizados registran "los actos de violencia urbana como los temblores de catastróficos desplazamientos nacionales y geopolíticos”. Kantaris sostiene que el desplazamiento es consustancial a la violencia porque constituye, en sí misma, "una dislocación, la expresión misma de un sistema de representaciones que excede y deshace todo marco de referencia", para, de este modo, trazar la presencia de "esa otra escena”, de una alteridad que sin duda materializa, en su incesante desplazamiento, una vida siempre irreductible.

Chloe Rutter, en "Silencio y violencia social. Discursos de VIH sida en la novela gay colombiana” nos ofrece una de las aristas de la violencia social: la exclusión que convoca el VIH sida a partir de la novela gay colombiana reciente: Un beso de Dick de Fernando Molano (1992), La virgen de los sicarios de Fernando Vallejo (1994) y Al diablo la maldita primavera de Alfredo Sánchez Baute (2002). Según Rutter, estas novelas constituyen "intervenciones frente aun silencio generalizado sobre el VIH sida”, y por lo tanto, cruzan la batalla discursiva que inscriben otras sexualidades frente a la heterosexualidad normativa. No obstante, la autora sostiene que la violencia social analizada por estas novelas traza un punto de partida -la homosexualidad- capaz de alcanzar otras prácticas políticas y culturales, y cuyo centro no es otro que una densa pregunta por la Nación: “Aun en contra de un esfuerzo tremendo por parte del discurso nacional para esconder y reprimir las sexualidades alternativas, el cuerpo del VIH sida, en su forma masculina o femenina señala la distancia entre la nación ‘real' y la nación soñada patriarcal y cristiana. El virus no es solo una violencia específica que ataca al cuerpo, sino una violencia más general que podríamos llamar, 'violencia social', que ataca los lazos afectivos alternativos”. Rutter inscribe una discusión sobre la visibilidad e identidad de otros sujetos, por cuanto el régimen de visualidad es también un campo de lucha capaz de interrogar la praxis política dentro del cuerpo social que, no lo olvidemos, erige la Nación como una fuerza de identidad.

Para María Mercedes Jaramillo, en “Las mujeres y la guerra”, los dramaturgos que se ocupan de la violencia nacional cristalizan un nudo histórico, un "movimiento entre pasado, presente y futuro” ocupado en capturar dimensiones íntimas de la experiencia más allá (o más acá) de la historiografía oficial. Para Jaramillo, los que sufren la guerra -las mujeres y los niños-, no pueden menos que transfigurar sus rostros en las piezas analizadas, pero se trata ciertamente de dos sujetos sociales que en medio de los extremos del conflicto armado, exponen la vida: desde los contrapuntos políticos e ideológicos que nos dibujan Mujeres en la guerra (2004) y A dónde el camino irá (2004) de Fernando Montes y Carlota Llano, y el rostro de los desaparecidos en la toma del Palacio de Justicia a la hora de ejercer una pregunta por la responsabilidad (La siempreviva, 1994), hasta el afán de supervivencia de la condición femenina frente a las oportunidades clausuradas (Femina Ludens, 1995). Como bien lo expresa la autora, en muchas de estas piezas teatrales el testimonio -la palabraconstituye un punto de partida, "pequeño fragmento de realidad que es parte de esta dolorosa historia colectiva hecha de inseguridades y de miedos, de peligros inminentes, de pérdidas, 
de muertes, sin embargo las mujeres le apuestan a la vida, al amor, a la solidaridad”. Lo que surge entonces frente a la violencia es la identidad: estas mujeres demuestran que no se puede renunciar a la identidad y que ésta nace justo en las miríadas de historias que son tanto individuales como colectivas; y es precisamente este entramado lo que estos testimonios, lo que estas obras teatrales, ansían comprender.

En el ensayo “¿Para vivir todos del mismo lado?: Representación, violencia y multiculturalismo en Colombia”, Nick Morgan, por medio de una miríada de discursos mediáticos se pregunta "cómo las maquinarias figurativas del país construyen las identidades que, en conjunto, conforman la categoría de ‘pueblo', y las rearticulan ante la crisis actual”, y de este modo ejerce una franca evaluación de las nociones de multiculturalismo y diversidad propuestas en la Constitución nacional de 1991. Sostiene el autor que estas “representaciones buscan incorporar lo marginal y lo periférico para fijarlo como parte de un imaginario social en el cual la categoría de 'pueblo' se encuentra conformada por 'narcoparamilitares', 'narcoguerrilleros', 'traquetos', 'secuestradores', 'sicarios', 'desplazados', 'recicladores', 'hampones', 'prostitutas’, ‘desechables’, 'parceros', 'pobres”, ‘negritos’, ‘indios’ y, con cada vez mayor frecuencia, 'terroristas'”. En fin, una multitud capaz de fracturar los límites de los regímenes de representación instituidos anula la posibilidad de erigir sujetos sociales de derechos. Morgan gira su perspectiva frente al reconocimiento constitucional de la diversidad y sostiene que "Mientras no haya un desafío sistemático a estos regímenes de representación, el énfasis formal en lo social y la promoción del multiculturalismo siempre serán deshechos por discursos informales en los cuales predominan el elitismo y el racismo. Las posibilidades de que las mayorías participen de forma significativa en la democracia colombiana se ven muy limitadas si no tienen voz, y si la minoría acomodada no las reconoce como interlocutores serios. Es decir, si el único diálogo posible en la Colombia actual es entre un sordo y un mudo, las perspectivas para una paz con justicia social en Colombia son muy tenues. En últimas, tenemos que preguntarnos si el multiculturalismo que se imagina para Colombia es de reconocimiento de los diversos grupos étnicos, y no de redistribución”.

Gregory Lobo en "La bella y la bestia; o, multiculturalismo y neoliberalismo en Colombia: entre consenso y dominación”, indaga hasta qué punto puede entenderse la inédita victoria de una afrocolombiana, Vanessa Mendoza, en el Reinado Nacional de la Belleza (2001), conforme a “una narrativa de la superación de la discriminación”. Según Lobo, "Dado que el Reinado ocupa un espacio bastante importante en el imaginario nacional se puede tomar la victoria como señal de que después de años y años de aislamiento, de enfrentar prejuicios, resistir la lógica de mestizaje que quería acabar con su propia existencia y lograr reconocimiento como identidad étnica en la nueva constitución, lo negro finalmente se volvió bello en Colombia”. Pero, de acuerdo con el autor, las contradicciones surgen al punto cuando se analiza el reinado de Mendoza desde la rearticulación hegemónica que convocó el enfrentamiento entre las exigencias del desarrollo capitalista en Colombia y la creciente politización de la identidad negra o afrocolombiana en las últimas décadas. Desde esta coyuntura, Gregory Lobo no puede menos que preguntarse por los resultados que las políticas de representación centradas en la raza inscriben dentro del cuerpo social: “¿ ¿sta victoria significa un verdadero avance en el país, un paso adelante hacia la soñada 
“democracia racial”? ¿O será que es algo más siniestro - un intento, ya sea inconsciente, de quebrar las dinámicas de politización de la población afrocolombiana, por rearticulación de los discursos negros resistentes en un discurso multiculturalista que no desafía nada? La respuesta, en últimas, tiene que ser, pues, ambas, lo cual no quiere decir que la clase dominante maquinaba la victoria de Mendoza para proteger sus intereses”.

"Las Nuevas Guerras y las violencias desplazadas”, incorpora dos ensayos ocupados en indagar la formación de sujetos excluidos y enfrentados con los procesos de modernización en América Latina. Al abrir la escala hacia las fronterizas Venezuela y Brasil, el desplazamiento de la violencia (y los discursos que la nombran) no puede menos que subrayar una pregunta por lo real, la realidad y las políticas de representación, precisamente cuando alcanza la vida de millones de latinoamericanos... Así, por ejemplo, en "Huellas de lo real. Testimonio y cine de la delincuencia en Venezuela y Colombia”, Luis Duno-Gottberg y Forrest Hylton sostienen que "Más acá de la realidad se abisma lo Real, eludiendo la sujeción del significante y, sin embargo, dejando trazos en la experiencia. Pensamos en instantes en los que la imaginación no consigue unir el acontecimiento a un concepto que lo abarque y contenga. Ante la mirada del espectador -o desde ésta- se proyecta un exceso que sólo comunica la resistencia a ser cabalmente representado. Esa opacidad y su efecto puestos en escena por intervenciones en lo literario o cinematográfico por parte de sujetos marginados, excluidos, violentados y violentos, es lo que llamamos aquí "la huella de lo Real”. Una huella que logra cristalizarse en el testimonio literario y cinematográfico de delincuentes, en una "narrativa de urgencia” cuyo exceso de significación trasciende toda identidad prefigurada: No nacimos pa' semilla (1990) del colombiano Alonso Salazar, La ley de la calle (1991) de los venezolanos Boris Muñoz y José Roberto Duque, Soy un delincuente (1976), del director venezolano Clemente de la Cerda, y Rodrigo D. No Futuro (1988), del colombiano Víctor Gaviria, constituyen el corpus de una "huella” cuya materialidad se manifiesta "en contradicción con la realidad y como un desplazamiento que señala los límites del lenguaje”, pero que sin embargo, al trazar una resistencia no pueden menos que retar, no sin ciertos peligros, todo tipo de filiaciones interpretativas.

Las novelas La virgen de los sicarios (1994), de Fernando Vallejo y Cidade de Deus (1997), de Paulo Lins, constituyen el centro del interés crítico de Lidia Santos en su artículo “Entre Dios y los Sicarios: las ‘Nuevas Guerras’ en la narrativa contemporánea de Colombia y Brasil”. Santos argumenta que una vía privilegiada para el análisis de estas novelas es examinarlas a partir de las obras de Jacques Derrida dedicadas al cosmopolitismo y la hospitalidad, en tanto corrientes progresistas contemporáneas cuyo fin no es otro que trascender el modelo económico neoliberal. Sostiene la autora: "el reconocimiento de que la naturaleza humana también comporta la maldad, siendo los valores que subyacen al cosmopolitismo una salvaguardia contra su diseminación. Por lo tanto, el crimen que hoy domina a Colombia no caracteriza la 'modernidad incompleta' (Schwarz), o la 'desmodernización’ (Pratt) de América Latina. Al contrario, él se integra completamente en el proyecto moderno, llegando a ser su más avanzada manifestación, especialmente por la tecnología de destrucción que utiliza. A través de las armas, Medellín se transforma en un sitio donde impera la inhospitalidad absoluta, la cual, por oposición, reafirma el principio moderno de la hospitalidad absoluta”. Para la autora, la lectura de las novelas 
La virgen de los sicarios y Cidade de Deus, ambas escritas durante la implantación de las reformas neoliberales en el subcontinente, "enseña que el proyecto de modernidad logró materializarse allí, mostrando en las versiones vernáculas su cara sucia”. De este modo, la "suciedad de las nuevas guerras latinoamericanas" flexionan, sin duda, la escritura: "La vuelta del realismo como estética se basa en el mismo principio: de tan preciso llega ya a borrar los contornos de lo visto y descrito, haciéndonos casi dudar del horror civilizado que nos está narrando".

Por último, quisiéramos agradecer el sostenido esfuerzo tanto de Mabel Moraña y Erika Braga como del Comité de Publicaciones del Instituto Internacional de Literatura Iberoamericana (IILI), por su apoyo en la edición del presente número monográfico. A ellos, siempre, nuestro agradecimiento.

\section{BIBLIOGRAFÍA}

Certeau, Michel de. La cultura en plural. Buenos Aires: Nueva Visión, 2004. 